Check for updates

Cite this: RSC Adv., 2017, 7, 28965

\title{
Detailed thermodynamic analysis of the activation parameters for the simple hydrolysis of acetic anhydride in the acetonitrile/water cosolvent system $\dagger$
}

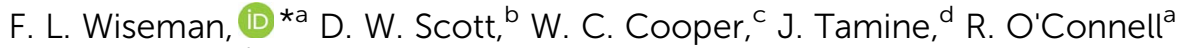 \\ and N. Mitchell ${ }^{\mathrm{b}}$
}

A detailed thermodynamic analysis of the activation parameters for the simple hydrolysis of acetic anhydride in an acetonitrile/water cosolvent system is presented. The activation parameters are obtained using regression analyses of the Eyring rate equation under iso-mole fraction and isodielectric conditions. The iso-mole fraction Eyring plots are linear, indicating the activation enthalpy and entropy are both temperature independent under these conditions. However, the isodielectric Eyring plots are non-linear, and the analysis shows both the activation entropy and activation enthalpy are strongly temperature dependent under isodielectric conditions. The thermodynamic analysis is complemented by linear solvent energy analysis and computational studies of possible transition structures, the latter showing that a concerted six-member ring structure with a single water molecule is the likely transition state.

Received 9th May 2017

Accepted 25th May 2017

DOI: 10.1039/c7ra05260j

rsc.li/rsc-advances fundamentally based quantitative analysis would serve a powerful complement, and perhaps provide additional information not otherwise tractable with LSER methods.

The most widely-used theory for analyzing reaction rates is the Eyring rate equation, which has proven to be quite adept for analyzing aqueous-phase reaction rate data.9,10 This celebrated theory is based upon the premise of a quasi-equilibrium between the reactant and transition states. The theory has its limitations, particularly in the case of fast reactions, but because of its inherent use of a thermodynamic construct in the form of the activation parameters, it allows for a conventional thermodynamic analysis. To the authors' knowledge an analysis of this kind has not yet been presented in the literature.

Thermodynamic analyses entail analyzing a measurable variable in response to a specified parameter space. A classic example is the response of reaction enthalpies to changes in temperature and pressure. Per the nature of Eyring theory, measuring the response of the activation parameters for a reaction requires that the temperature be part of that parameter space. Any other measurable variable of interest then requires studying the reaction over a suitable range for that variable as well. For studying the effects of a cosolvent system, which is the focus of this work, generating the usual iso-mole fraction Eyring plots is required. But in addition, Eyring plots must be generated in which at least one other measurable solvent parameter is held constant. This type of analysis is certainly not traditional, and requires a more extensive experimental protocol. The benefit of this complementary suite of Eyring analyses is the contributions from the temperature, the

\footnotetext{
${ }^{a}$ Department of Chemistry, Davis \& Elkins College, Elkins, WV 26241, USA. E-mail: wisemanf@dewv.edu

${ }^{b}$ Department of Chemistry, East Tennessee State University, Johnson City, TN 37614, USA

'Department of Chemistry, Eastern New Mexico University, Portales, NM 88130, USA ${ }^{d}$ Chevron Science Center, Chemistry, Pittsburgh, PA 15260, USA

$\dagger$ Electronic supplementary information (ESI) available. See DOI: 10.1039/c7ra05260j
} 
mole fraction, and other solvent parameters of interest can be individually analyzed in separate thermodynamic terms.

Because specific solute-solvent interactions cannot be directly measured, bulk properties must instead be chosen in the thermodynamic analysis. The property of choice in this work is the relative permittivity, which often makes a significant contribution to condensed-phase reaction rates, and has received much attention in the literature. Historical work includes a systematic qualitative description by Hughes and Ingold, ${ }^{11-14}$ and development of various quantitative expressions relating reaction rate constants to the relative permittivity. ${ }^{15-19}$ For the test reaction, the authors have chosen the simple hydrolysis of acetic anhydride because it has been well characterized, ${ }^{\mathbf{2 0}-23}$ and has served as a benchmark reaction for certain chemical engineering processes. ${ }^{24}$ Finally, the authors have chosen the acetonitrile/water cosolvent system for this work. This system is miscible, well characterized, and shows a strong dependence of the relative permittivity on mole fraction.

This work also includes an analysis of the rate data using the LSER equation of Kamlet and Taft, ${ }^{4-7}$ and results of computational studies of selected transition states. Results of these analyses provide information that complements the thermodynamic analysis.

\section{Theory}

\section{Thermodynamic treatment of the Eyring activation parameters}

Activation parameters depend upon any variable that affects the energies and entropies of the reactant and transition states. The number of such variables is rather extensive, and individually tracking all of them is experimentally impossible. Among the ones easier to track, and the ones used in this work, are the temperature, cosolvent mole fraction, and relative permittivity. As such, the analysis presented in this article allows the solution relative permittivity to be separately quantified, which is notable since distinguishing bulk medium effects from specific interactive substrate-solvent effects is generally quite difficult.

The total differential for the activation enthalpy $\left(\Delta H^{\ddagger}\right)$ in terms of the temperature $(T)$, the cosolvent mole fraction $(X)$, and the relative permittivity $(\varepsilon)$ is:

$$
\mathrm{d} \Delta H^{\ddagger}=\left(\frac{\partial \Delta H^{\ddagger}}{\partial T}\right)_{X, \varepsilon} \mathrm{d} T+\left(\frac{\partial \Delta H^{\ddagger}}{\partial X}\right)_{\varepsilon, T} \mathrm{~d} X+\left(\frac{\partial \Delta H^{\ddagger}}{\partial \varepsilon}\right)_{X, T} \mathrm{~d} \varepsilon
$$

$X$ can be for either component; in this work $X$ is the water mole fraction. Eyring plots require variation in temperature; hence $\left(\frac{\partial \Delta H^{\ddagger}}{\partial T}\right)_{X}$ and $\left(\frac{\partial \Delta H^{\ddagger}}{\partial T}\right)_{\varepsilon}$ are key terms in the analysis. From eqn (1) these terms are:

$$
\begin{gathered}
\left(\frac{\partial \Delta H^{\ddagger}}{\partial T}\right)_{X}=\left(\frac{\partial \Delta H^{\ddagger}}{\partial T}\right)_{X, \varepsilon}+\left(\frac{\partial \Delta H^{\ddagger}}{\partial \varepsilon}\right)_{X, T}\left(\frac{\partial \varepsilon}{\partial T}\right)_{X} \\
\left(\frac{\partial \Delta H^{\ddagger}}{\partial T}\right)_{\varepsilon}=\left(\frac{\partial \Delta H^{\ddagger}}{\partial T}\right)_{X, \varepsilon}+\left(\frac{\partial \Delta H^{\ddagger}}{\partial X}\right)_{\varepsilon, T}\left(\frac{\partial X}{\partial T}\right)_{\varepsilon}
\end{gathered}
$$

Terms such as $\left(\frac{\partial \Delta H^{*}}{\partial T}\right)_{X, \varepsilon}$, in which two independent variables are held constant, are hereafter called double constraint differential terms. These terms cannot be directly measured in any single cosolvent system because one independent variable cannot change while the other two are constant. However, they can be functionally related to measurable terms. The values for these double constraint differential terms reveal useful information about the structural and electrostatic nature of the transition state.

$\left(\frac{\partial \Delta H^{\ddagger}}{\partial T}\right)_{X, \varepsilon}$ can be identified as the activation heat capacity $\left(\Delta C_{\mathrm{p}}^{\ddagger}\right.$ ) under conditions of constant pressure, mole fraction, and relative permittivity. Eqn (2) and (3) therefore become:

$$
\begin{gathered}
\left(\frac{\partial \Delta H^{\ddagger}}{\partial T}\right)_{X}=\Delta C_{\mathrm{p}}^{\ddagger}+\left(\frac{\partial \Delta H^{\ddagger}}{\partial \varepsilon}\right)_{X, T}\left(\frac{\partial \varepsilon}{\partial T}\right)_{X} \\
\left(\frac{\partial \Delta H^{\ddagger}}{\partial T}\right)_{\varepsilon}=\Delta C_{\mathrm{p}}^{\ddagger}+\left(\frac{\partial \Delta H^{\ddagger}}{\partial X}\right)_{\varepsilon, T}\left(\frac{\partial X}{\partial T}\right)_{\varepsilon}
\end{gathered}
$$

Since $\left(\frac{\partial \Delta S}{\partial T}\right)_{X, \varepsilon}=\frac{\Delta C_{\mathrm{p}}^{\ddagger}}{T}$, the companion expressions for the activation entropy are:

$$
\begin{aligned}
\left(\frac{\partial \Delta S^{\ddagger}}{\partial T}\right)_{X} & =\frac{\Delta C_{\mathrm{p}}^{\ddagger}}{T}+\left(\frac{\partial \Delta S^{\ddagger}}{\partial \varepsilon}\right)_{X, T}\left(\frac{\partial \varepsilon}{\partial T}\right)_{X} \\
\left(\frac{\partial \Delta S^{\ddagger}}{\partial T}\right)_{\varepsilon} & =\frac{\Delta C_{\mathrm{p}}^{\ddagger}}{T}+\left(\frac{\partial \Delta S^{\ddagger}}{\partial X}\right)_{\varepsilon, T}\left(\frac{\partial X}{\partial T}\right)_{\varepsilon}
\end{aligned}
$$

Iso-mole fraction Eyring plots are generally linear, in which case $\left(\frac{\partial \Delta H^{\ddagger}}{\partial T}\right)_{X}$ and $\left(\frac{\partial \Delta S^{\ddagger}}{\partial T}\right)_{X}$ are zero. Under these conditions

$$
\begin{aligned}
\left(\frac{\partial \Delta H^{\ddagger}}{\partial \varepsilon}\right)_{X, T} \text { and }\left(\frac{\partial \Delta S^{\ddagger}}{\partial \varepsilon}\right)_{X, T} \text { are: } & \\
\left(\frac{\partial \Delta H^{\ddagger}}{\partial \varepsilon}\right)_{X, T} & =-\Delta C_{\mathrm{p}}^{\ddagger}\left(\frac{\partial T}{\partial \varepsilon}\right)_{X} \\
\left(\frac{\partial \Delta S^{\ddagger}}{\partial \varepsilon}\right)_{X, T} & =-\frac{\Delta C_{\mathrm{p}}^{\ddagger}}{T}\left(\frac{\partial T}{\partial \varepsilon}\right)_{X}
\end{aligned}
$$

The differential expression for $\Delta G^{\ddagger}=\Delta H^{\ddagger}-T \Delta S^{\ddagger}$ under isomole fraction and isothermal conditions is:

$$
\left(\frac{\partial \Delta G^{\ddagger}}{\partial \varepsilon}\right)_{X, T}=\left(\frac{\partial \Delta H^{\ddagger}}{\partial \varepsilon}\right)_{X, T}-T\left(\frac{\partial \Delta S^{\ddagger}}{\partial \varepsilon}\right)_{X, T}
$$

Substituting the terms in eqn (8) and (9) into (10) yields:

$$
\left(\frac{\partial \Delta G^{\ddagger}}{\partial \varepsilon}\right)_{X, T}=-\Delta C_{\mathrm{p}}^{\ddagger}\left(\frac{\partial T}{\partial \varepsilon}\right)_{X}+T\left[\frac{\Delta C_{\mathrm{p}}^{\ddagger}}{T}\left(\frac{\partial T}{\partial \varepsilon}\right)_{X}\right]=0
$$


This remarkable result stems from the linearity of the isomole fraction Eyring plots, and is entirely general! A similar analysis for linear isodielectric Eyring plots leads to $\left(\frac{\partial G^{\ddagger}}{\partial X}\right)_{\varepsilon, T}=0$.

As will be shown, the isodielectric Eyring plots for the reaction system studied in this work are not linear. Whether this is a general trend remains to be determined, as isodielectric Eyring plots are not commonplace in the literature. One explanation for this non-linearity is that either or both terms, $\left(\frac{\partial \Delta H^{\ddagger}}{\partial T}\right)_{\varepsilon}$ and $\left(\frac{\partial \Delta S^{\ddagger}}{\partial T}\right)_{\varepsilon}$, is not zero. However, because of this ambiguity, individual numeric values for these terms cannot be determined from the isodielectric Eyring plots alone. Resolving this ambiguity requires these terms be related to measurable terms from the linear iso-mole fraction plots. The key relationships required for this analysis are derived in the following paragraphs.

Noting that $\left(\frac{\partial \Delta H^{*}}{\partial \varepsilon}\right)_{T}=\left(\frac{\partial \Delta H^{\ddagger}}{\partial X}\right)_{T}\left(\frac{\partial X}{\partial \varepsilon}\right)_{T} \quad$ and $\left(\frac{\partial \Delta S^{\ddagger}}{\partial \varepsilon}\right)_{T}=\left(\frac{\partial \Delta S^{\ddagger}}{\partial X}\right)_{T}\left(\frac{\partial X}{\partial \varepsilon}\right)_{T}$, the expression for $\left(\frac{\partial \Delta G^{\ddagger}}{\partial \varepsilon}\right)_{T}$ is:

$$
\left(\frac{\partial \Delta G^{\ddagger}}{\partial \varepsilon}\right)_{T}=\left[\left(\frac{\partial \Delta H^{\ddagger}}{\partial X}\right)_{T}-T\left(\frac{\partial \Delta S^{\ddagger}}{\partial X}\right)_{T}\right]\left(\frac{\partial X}{\partial \varepsilon}\right)_{T}
$$

As will be shown, the plot of $\left(\frac{\partial \Delta G^{\ddagger}}{\partial \varepsilon}\right)_{T}\left(\frac{\partial \varepsilon}{\partial X}\right)_{T} v s . T$ is linear, hence the slope is $-\left(\frac{\partial \Delta S^{\ddagger}}{\partial X}\right)_{T}$ and the intercept is $\left(\frac{\partial \Delta H^{\ddagger}}{\partial X}\right)_{T}$.

Treating the mole fraction as the independent variable in eqn (1) leads to the following expression:

$$
\left(\frac{\partial \Delta H^{\ddagger}}{\partial X}\right)_{T}=\left(\frac{\partial \Delta H^{\ddagger}}{\partial X}\right)_{\varepsilon, T}+\left(\frac{\partial \Delta H^{\ddagger}}{\partial \varepsilon}\right)_{X, T}\left(\frac{\partial \varepsilon}{\partial X}\right)_{T}
$$

Combining eqn (8) and (13) yields:

$$
\left(\frac{\partial \Delta H^{\ddagger}}{\partial X}\right)_{\varepsilon, T}=\left(\frac{\partial \Delta H^{\ddagger}}{\partial X}\right)_{T}+\Delta C_{\mathrm{p}}^{\ddagger}\left(\frac{\partial T}{\partial \varepsilon}\right)_{X}\left(\frac{\partial \varepsilon}{\partial X}\right)_{T}
$$

Finally, combining eqn (5) and (14) yields:

$$
\begin{aligned}
\left(\frac{\partial \Delta H^{\ddagger}}{\partial T}\right)_{\varepsilon}= & \Delta C_{\mathrm{p}}^{\ddagger}+\left[\left(\frac{\partial \Delta H^{\ddagger}}{\partial X}\right)_{T}\right. \\
& \left.+\Delta C_{\mathrm{p}}^{\ddagger}\left(\frac{\partial T}{\partial \varepsilon}\right)_{X}\left(\frac{\partial \varepsilon}{\partial X}\right)_{T}\right]\left(\frac{\partial X}{\partial T}\right)_{\varepsilon}\left(\frac{\partial \Delta H^{\ddagger}}{\partial T}\right)_{\varepsilon} \\
= & \Delta C_{\mathrm{p}}^{\ddagger}+\left[\left(\frac{\partial \Delta H^{\ddagger}}{\partial X}\right)_{T}-\Delta C_{\mathrm{p}}^{\ddagger}\left(\frac{\partial T}{\partial X}\right)_{\varepsilon}\right]\left(\frac{\partial X}{\partial T}\right)_{\varepsilon}\left(\frac{\partial \Delta H^{\ddagger}}{\partial T}\right)_{\varepsilon} \\
= & \left(\frac{\partial \Delta H^{\ddagger}}{\partial X}\right)_{T}\left(\frac{\partial X}{\partial T}\right)_{\varepsilon}
\end{aligned}
$$

Eqn (15) is true provided $\left(\frac{\partial \Delta H^{\ddagger}}{\partial T}\right)_{X}=0$. Since $\left(\frac{\partial \Delta H^{*}}{\partial T}\right)_{\varepsilon}=\left(\frac{\partial \Delta H^{\ddagger}}{\partial X}\right)_{\varepsilon}\left(\frac{\partial X}{\partial T}\right)_{\varepsilon}$, then it follows that $\left(\frac{\partial \Delta H^{\ddagger}}{\partial X}\right)_{\varepsilon}=\left(\frac{\partial \Delta H^{\ddagger}}{\partial X}\right)_{T}$ if $\left(\frac{\partial \Delta H^{\ddagger}}{\partial T}\right)_{X}=0$. The companion expression for $\left(\frac{\partial \Delta S^{\ddagger}}{\partial T}\right)_{\varepsilon}$, which is true if $\left(\frac{\partial \Delta S^{\ddagger}}{\partial T}\right)_{X}=0$, is:

$$
\left(\frac{\partial \Delta S^{\ddagger}}{\partial T}\right)_{\varepsilon}=\left(\frac{\partial \Delta S^{\ddagger}}{\partial X}\right)_{T}\left(\frac{\partial X}{\partial T}\right)_{\varepsilon}
$$

\section{Empirical relationships for the cosolvent terms}

Expressions for $\left(\frac{\partial T}{\partial \varepsilon}\right)_{X}$ and $\left(\frac{\partial \varepsilon}{\partial X}\right)_{T}$ can be determined from polynomial regression analyses of experimental data for the cosolvent system. Expressions for $\left(\frac{\partial X}{\partial T}\right)_{\varepsilon}$ can then be calculated using the chain rule, or by direct regression analysis of the data using polynomials, as is done in this work. For the thermodynamic analyses, regression polynomials are also required for the rate constants in terms of $X$ for each temperature. The correlation coefficients for the polynomials in this work are generally 0.999 or better, and the "experimentally equivalent" errors in the polynomial fits are presumably comparable to the actual experimental errors.

For acetonitrile/water mixtures, linear polynomials are adequate for expressing $\varepsilon$ in terms of $X$ and $T$, but a secondorder polynomial is better for expressing $X$ in terms of $T$. The general expressions where the $a$ 's, $b$ 's and $c_{\varepsilon}$ are the polynomial fitting parameters are:

$$
\begin{gathered}
\varepsilon_{T}=a_{T} X+b_{T} \\
\varepsilon_{X}=a_{X} T+b_{X} \\
X_{\varepsilon}=a_{\varepsilon} T^{2}+b_{\varepsilon} T+c_{\varepsilon}
\end{gathered}
$$

in which the subscript refers to the variable being held constant. In thermodynamics, parameters appearing in equations for which a variable is held constant are generally dependent upon that variable as well. This is the case here, and it is found that $a_{T}$ and $a_{X}$ are well represented by linear functions in $T$ and $X$, respectively, i.e.:

$$
\begin{aligned}
& a_{T}=a_{T}^{\prime} T+b^{\prime}{ }_{T} \\
& a_{X}=a_{X}^{\prime} X+b^{\prime}{ }_{X}
\end{aligned}
$$

Corresponding expressions for $a_{\varepsilon}$ and $b_{\varepsilon}$ are not shown here since they are not necessary for the analysis. From these expressions, the full series of partial derivatives relating $\varepsilon, T$, and $X$ is:

$$
\left(\frac{\partial \varepsilon}{\partial X}\right)_{T}=a_{T}=a_{T}^{\prime} T+b_{T}^{\prime}
$$




$$
\begin{gathered}
\left(\frac{\partial \varepsilon}{\partial T}\right)_{X}=a_{X}=a_{X}^{\prime} X+b_{X}^{\prime} \\
\left(\frac{\partial X}{\partial T}\right)_{\varepsilon}=2 a_{\varepsilon} T+b_{\varepsilon}
\end{gathered}
$$

\section{General expressions for the thermodynamic activation terms}

Using the polynomials from the previous subsection yields the following general expressions for the double constraint differential terms:

$$
\begin{gathered}
\left(\frac{\partial \Delta H^{\ddagger}}{\partial \varepsilon}\right)_{X, T}=-\frac{\Delta C_{\mathrm{p}}^{\ddagger}}{a_{X}^{\prime} X+b_{X}^{\prime}} \\
\left(\frac{\partial \Delta S^{\ddagger}}{\partial \varepsilon}\right)_{X, T}=-\frac{\Delta C_{\mathrm{p}}^{\ddagger}}{\left(a_{X}^{\prime} X+b_{X}^{\prime}\right) T} \\
\left(\frac{\partial \Delta H^{\ddagger}}{\partial X}\right)_{\varepsilon, T}=\left(\frac{\partial \Delta H^{\ddagger}}{\partial X}\right)_{T}+\frac{\Delta C_{\mathrm{p}}^{\ddagger}\left(a_{T}^{\prime} T+b_{T}^{\prime}\right)}{a_{X}^{\prime} X+b_{X}^{\prime}} \\
\left(\frac{\partial \Delta S^{\ddagger}}{\partial X}\right)_{\varepsilon, T}=\left(\frac{\partial \Delta S^{\ddagger}}{\partial X}\right)_{T}+\frac{\Delta C_{\mathrm{p}}^{\ddagger}\left(a_{T}^{\prime} T+b_{T}^{\prime}\right)}{\left(a_{X}^{\prime} X+b_{X}^{\prime}\right) T}
\end{gathered}
$$

The expressions for $\left(\frac{\partial \Delta H^{\ddagger}}{\partial T}\right)_{\varepsilon}$ and $\left(\frac{\partial \Delta S^{\ddagger}}{\partial T}\right)_{\varepsilon}$ are:

$$
\begin{aligned}
& \left(\frac{\partial \Delta H^{\ddagger}}{\partial T}\right)_{\varepsilon}=\left(2 a_{\varepsilon} T+b_{\varepsilon}\right)\left(\frac{\partial \Delta H^{\ddagger}}{\partial X}\right)_{T} \\
& \left(\frac{\partial \Delta S^{\ddagger}}{\partial T}\right)_{\varepsilon}=\left(2 a_{\varepsilon} T+b_{\varepsilon}\right)\left(\frac{\partial \Delta S^{\ddagger}}{\partial X}\right)_{T}
\end{aligned}
$$

Since the series of iso-mole fraction Eyring plots in this work are linear, $\left(\frac{\partial \Delta H^{\ddagger}}{\partial X}\right)_{T}$ and $\left(\frac{\partial \Delta S^{\ddagger}}{\partial X}\right)_{T}$ are independent of $\mathrm{T}$. Therefore, the integrated expressions from eqn (29) and (30) are:

$$
\begin{gathered}
\Delta H^{\ddagger}=\Delta H_{\mathrm{r}}^{\ddagger}+\left[a_{\varepsilon}\left(T^{2}-T_{\mathrm{r}}^{2}\right)+b_{\varepsilon}\left(T-T_{\mathrm{r}}\right)\right]\left(\frac{\partial \Delta H^{\ddagger}}{\partial X}\right)_{T} \\
\Delta S^{\ddagger}=\Delta S_{\mathrm{r}}^{\ddagger}+\left[a_{\varepsilon}\left(T^{2}-T_{\mathrm{r}}^{2}\right)+b_{\varepsilon}\left(T-T_{\mathrm{r}}\right)\right]\left(\frac{\partial \Delta S^{\ddagger}}{\partial X}\right)_{T}
\end{gathered}
$$

in which $T_{\mathrm{r}}$ is a reference temperature and $\Delta H_{\mathrm{r}}^{\ddagger}$ and $\Delta S_{\mathrm{r}}^{\ddagger}$ are the values at $T_{\mathrm{r}}$.

In addition to temperature-dependent activation parameters, curvature in Eyring plots can be due to several other factors as well. One is the reversible formation of an intermediate. However, in this work this possibility can be summarily ruled out since, as will be shown, the curvature in the isodielectric plots is concave upward. The reversible formation of an intermediate experimentally has been shown to cause a slight downward curvature, and only at temperatures below $\sim 15^{\circ} \mathrm{C}$ for the simple hydrolysis of acetic anhydride..$^{25,26}$ Another possibility is the effect of the activation heat capacity term. However, it has been the authors' experience that for Eyring plots exhibiting any noticeable curvature, $\Delta C_{\mathrm{p}}^{\ddagger}$ must be unrealistically large to adequately account for the curvature. This work is no exception, as regression values from the isodielectric plots yield $\Delta C_{\mathrm{p}}^{\ddagger}$ values on the order of $800 \mathrm{~J} \mathrm{~K}^{-1} \mathrm{~mol}^{-1}$ ! Another possible explanation is the existence of more than one thermodynamically accessible transition state. The different transition states can either be different in structure with the same molecularity, or have different molecularities. However, computational studies, which are described later, strongly suggest only one accessible transition state exists.

\section{Empirical relationship between the observed rate constant} $\left(k_{\text {obs}}\right)$ and the cosolvent relative permittivity Assuming a linear dependence of $\left(\frac{\partial \Delta G^{\star}}{\partial \varepsilon}\right)_{T}$ on $\varepsilon$ renders the
following expression:

$$
\mathrm{d} \Delta G^{\star}=(a+b \varepsilon) \mathrm{d} \varepsilon
$$

in which $a$ and $b$ are empirical parameters. Integrating eqn (33) yields:

$$
\Delta G^{\ddagger}=\Delta G_{1}^{\ddagger}+(\varepsilon-1)[a+1 / 2 b(\varepsilon+1)]
$$

in which $\Delta G_{1}^{\ddagger}$ is the activation free energy for $\varepsilon=1$. Using the Eyring equation, eqn (34) can be recast as:

$$
\ln k_{\mathrm{obs}}=\ln k_{1, \mathrm{obs}}-\frac{(\varepsilon-1)[a+1 / 2 b(\varepsilon+1)]}{R T}
$$

\section{The Eyring model for this work}

Results of computational studies, discussed in the computational section, clearly show that the transition state contains only one water molecule. Therefore, the observed rate constant, which is pseudo first-order, is:

$$
k_{\mathrm{obs}}=k\left[\mathrm{H}_{2} \mathrm{O}\right]
$$

in which $k$ is the second-order Eyring rate constant. The Eyring rate equation can therefore be cast as:

$$
Y=\Delta S^{\ddagger}-\frac{\Delta H^{\ddagger}}{T}
$$

in which $Y$ is $R\left\{\ln \frac{h k_{\mathrm{obs}}}{k_{\mathrm{B}} T}-\ln \left(\frac{\left[\mathrm{H}_{2} \mathrm{O}\right]}{\mathrm{mol} \mathrm{dm}^{-3}}\right)\right\}$, where $k_{\mathrm{B}}$ is Boltzmann's constant and $h$ is Planck's constant. Finally, combining eqn (31), (32), and (37) yields the following expression that is used for the isodielectric Eyring plots generated in this work:

$$
\begin{aligned}
Y= & \Delta S_{\mathrm{r}}^{\ddagger}-\frac{\Delta H_{\mathrm{r}}^{\ddagger}}{T}+\left[a_{\varepsilon}\left(T^{2}-T_{\mathrm{r}}^{2}\right)+b_{\varepsilon}\left(T-T_{\mathrm{r}}\right)\right]\left[\left(\frac{\partial \Delta S^{\ddagger}}{\partial X}\right)_{T}\right. \\
& \left.-\frac{1}{T}\left(\frac{\partial \Delta H^{\ddagger}}{\partial X}\right)_{T}\right]
\end{aligned}
$$




\section{Experimental}

Acetic anhydride (Baker, A.C.S., reagent) and acetonitrile (Fisher Scientific, A.C.S., certified) were used as received. Reaction solutions were prepared solely with deionized water and acetonitrile. Relative permittivity data for the acetonitrile/ water solutions was taken from ref. 33. Temperatures were maintained at $\pm 0.01{ }^{\circ} \mathrm{C}$ using a water bath and a Thermo Scientific Haake SC 100 water circulator. The water bath was placed on a magnetic stirrer to allow the reaction solutions to be continuously stirred. One drop of acetic anhydride was used per $\sim 20 \mathrm{~mL}$ of solution. The $\mathrm{pH}$ technique was used ${ }^{25,26}$ for acquiring the rate data. For most of the studies the reaction time and the $\mathrm{pH}$ were monitored manually. The $\mathrm{pH}$ was measured using an Accumet Model $15 \mathrm{pH}$ meter set to read to $0.001 \mathrm{pH}$ unit, and equipped with a Thermo Scientific Orion Ross electrode. The electrode was periodically calibrated using buffer solutions at pH 5.00 and 3.00. The initial pH for the reaction solutions was between 4.0 and 5.0 , and the $\mathrm{pH}$ ranged from 0.15 to $0.4 \mathrm{pH}$ unit during the course of the reactions. The reactions were monitored at least 2.5 half lives, and each data point was at least triplicate (generally more). Rate constants were measured at 15.0, 20.0, 25.0, 30.0, 35.0, 40.0, $45.0,50.0$, and $55.0^{\circ} \mathrm{C}$ for water mole fractions ranging from 0.790 to 1.000 . The raw pH-time data was fitted using nonlinear regression analysis with the standard non-buffer $\mathrm{pH}$ rate expression..$^{26} \mathrm{~A}$ typical $\mathrm{pH}$ rate curve is shown in Fig. 1. Fifteen to forty data points were taken for each trial, depending upon the half-life, and correlation coefficients ranged from 0.9999 for the faster reactions to 0.99999 or better for the slower reactions.

\section{Computational results}

The quantum mechanical computations were conducted using a Spartan Parallel Version ${ }^{27}$ on a $3.2 \mathrm{GHz}$ dual quad-core MacPro with an SSD drive and 24 GB physical RAM, which was run with a MacOS 10.6.8 booted into the 64-bit kernel. Diligent geometry searches located transition structures $\mathrm{A}$ to $\mathrm{E}$ as shown in Table 1. These structures possessed a single imaginary frequency.

Possible transition states were investigated in vacuo using a variety of methods and basis sets. However, RB3LYP/6-31G* was systematically used to more thoroughly investigate the transition states. This combination of method and basis set generally yields the smallest average deviation from experimental values. ${ }^{28}$ For instance, the computational value of $63.1 \mathrm{~kJ}$ $\mathrm{mol}^{-1}$ for the enthalpy of acetic anhydride hydrolysis obtained with RB3LYP/6-31G* agrees quite well with the literature value of $58.5 \mathrm{~kJ} \mathrm{~mol}^{-1}$. For this reason, only the computational results from the RB3LYP/6-31G* analyses are shown in Table 1. Nonetheless, other combinations of methods and basis sets consistently show structure B to be have the lowest activation free energy.

Optimizations were also conducted with the SM8 model $^{29}$ in water, dimethyl sulfoxide, and acetonitrile. Activation parameters were calculated using the optimized reactant and transition states for structures A to E. An upper bound for the activation free energy for structure F was estimated based upon $\operatorname{CCSD}(\mathrm{T}) /$ cc-pVTZ and G3 energies for the acetyl cation and acetate anion.

Absolute values for the energies of the individual species vary somewhat due to non-compliance with the hyperhomodesmotic criteria. ${ }^{30}$ However, the activation parameters are calculated from the energy difference between the reaction and transition

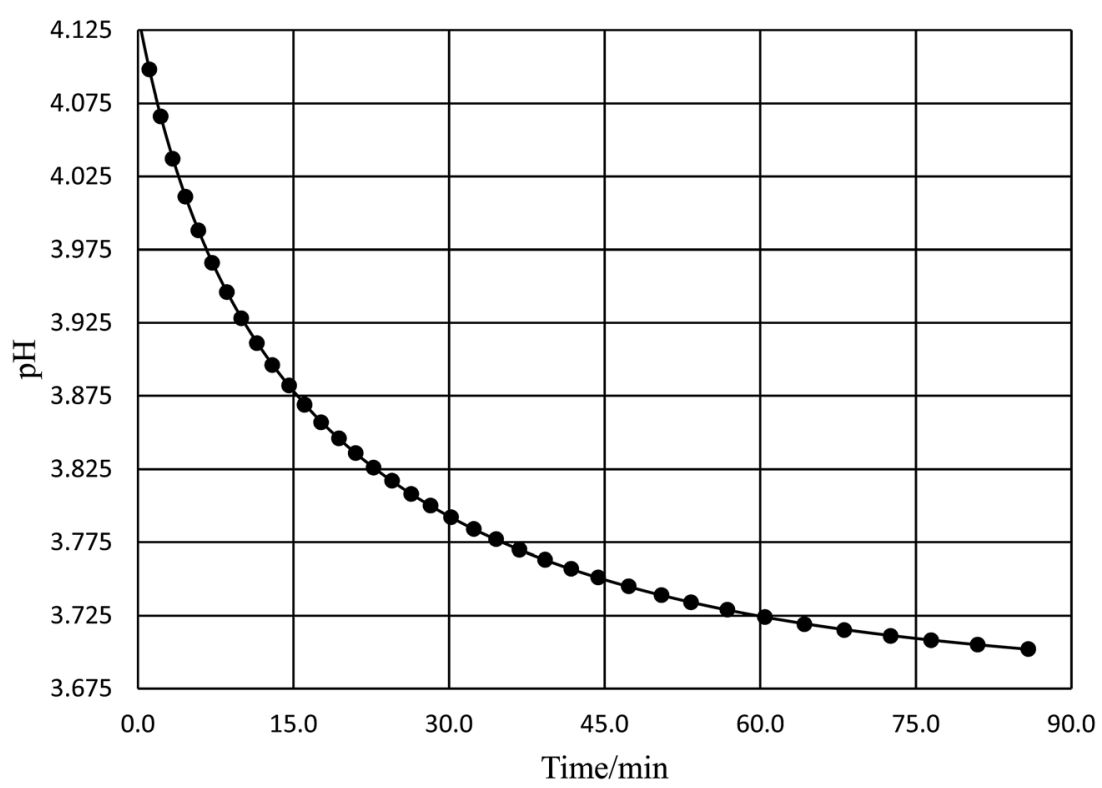

Fig. 1 A typical plot of $\mathrm{pH}$ vs. time for the simple hydrolysis of acetic anhydride. This plot is for the acetonitrile/water system at $36.0{ }^{\circ} \mathrm{C}$ and a water mole fraction of 0.8346 . The non-linear regression analysis uses the non-buffer version of the $\mathrm{pH}$ rate equation, which is, $\mathrm{pH}=a-\log \left\{\sqrt{1+b\left[1-c \mathrm{e}^{-k t}\right]}-1\right\},{ }^{25,26}$ where $a, b, c$, and $k$ (the rate constant) are the fitting parameters. The analysis result yields $k=$ $0.02676( \pm 0.00004) \mathrm{min}^{-1}$ and a correlation coefficient of 0.999997 . 
Table 1 Computational results for various transition states (TS) for simple acetic anhydride hydrolysis. See the text for a discussion of the computational methods. The activation free energies are calculated for $25^{\circ} \mathrm{C}$. TS A convergence required use of the SM 8 model in the optimization

\begin{tabular}{|c|c|c|c|c|c|c|}
\hline TS code & TS structure & $\begin{array}{l}\mu / \mathrm{D} \\
\text { (aqueous) }\end{array}$ & Products & $\begin{array}{l}\Delta H^{\ddagger} / \mathrm{kJ} \\
\mathrm{mol}^{-1}\end{array}$ & $\begin{array}{l}\Delta S^{\ddagger} / \mathrm{J} \\
\mathrm{K}^{-1} \mathrm{~mol}^{-1}\end{array}$ & $\begin{array}{l}\Delta G^{\ddagger} / \mathrm{kJ} \\
\mathrm{mol}^{-1}\end{array}$ \\
\hline A & & 14.4 & $\begin{array}{l}\mathrm{CH}_{3} \mathrm{CO}_{2}^{-} \\
\mathrm{CH}_{3} \mathrm{CO}_{2} \mathrm{H}_{2}^{+}\end{array}$ & 97.3 & -142.3 & 139.7 \\
\hline B & & 1.6 & $2 \mathrm{CH}_{3} \mathrm{CO}_{2} \mathrm{H}$ & 39.9 & -156.6 & 86.6 \\
\hline $\mathrm{C}$ & & 8.5 & $2 \mathrm{CH}_{3} \mathrm{CO}_{2} \mathrm{H}$ & 108.6 & -149.8 & 153.3 \\
\hline & & & $\begin{array}{l}2 \mathrm{CH}_{3} \mathrm{CO}_{2} \mathrm{H} \\
\mathrm{H}_{2} \mathrm{O}\end{array}$ & & & \\
\hline D & & 4.0 & & 19.8 & -307.9 & 111.6 \\
\hline $\mathrm{E}$ & & 5.1 & $\begin{array}{l}\mathrm{CH}_{3} \mathrm{CO}_{2} \mathrm{H} \\
\mathrm{CH}_{2} \mathrm{CO}\end{array}$ & 146.1 & 3.6 & 145.0 \\
\hline $\mathrm{F}$ & & - & $\begin{array}{l}\mathrm{CH}_{3} \mathrm{CO}_{2}^{-} \\
\mathrm{CH}_{3} \mathrm{CO}^{+}\end{array}$ & - & - & 191.4 \\
\hline
\end{tabular}

states, and are expected to have much smaller computational errors.

These computational results clearly support a concerted, one-water molecule transition state, which is contrary to conventional thought that at least two water molecules are structurally involved in the transition state. ${ }^{31,32}$ Computational results suggest that the entropic cost is too great for the meager energy payoff of adding additional water molecules in the transition state.

\section{Analysis results}

\section{Numeric expressions for the thermodynamic terms}

Fig. 2 shows the kinetic rate constants plotted as $-\log \left(k_{\mathrm{obs}}\right) v s$. $X_{\text {water }}$. The isothermal, isodielectric, and iso-mole fraction lines are color coded. The rate constants along the iso-mole fraction lines have been analyzed using eqn (37), and the plots are shown in Fig. 3. The iso-mole fraction Eyring plots are all linear, indicating that $\left(\frac{\partial \Delta H^{\ddagger}}{\partial T}\right)_{X}$ and $\left(\frac{\partial \Delta S^{\ddagger}}{\partial T}\right)_{X}$ are zero. Table 2 shows the activation enthalpy and entropy from the regression analyses, and the values for the activation free energies at $25^{\circ} \mathrm{C}$.

The experimental data for the acetonitrile/water system presented in ref. 33 has been fitted using eqn (17), and numeric results for the parameters are shown in Table 3. A linear fit using these values yields the following expression for $\left(\frac{\partial \varepsilon}{\partial T}\right)_{X}$ :

$$
\left(\frac{\partial \varepsilon}{\partial T}\right)_{X}=-\left(0.371 \mathrm{~K}^{-1}\right) X_{\text {water }}+0.027 \mathrm{~K}^{-1}
$$

Using eqn (25), (26), and (39), the expressions for $\left(\frac{\partial \Delta H^{\ddagger}}{\partial \varepsilon}\right)_{X, T}$ and $\left(\frac{\partial \Delta S^{\ddagger}}{\partial \varepsilon}\right)_{X, T}$ are:

$$
\begin{aligned}
\left(\frac{\partial \Delta H^{\ddagger}}{\partial \varepsilon}\right)_{X, T} & =\frac{\Delta C_{\mathrm{p}}^{\ddagger}}{\left(0.371 \mathrm{~K}^{-1}\right) X_{\text {water }}-0.027 \mathrm{~K}^{-1}} \\
\left(\frac{\partial \Delta S^{\ddagger}}{\partial \varepsilon}\right)_{X, T} & =\frac{\Delta C_{\mathrm{p}}^{\ddagger}}{\left[(0.371) X_{\text {water }}-0.027\right](T / \mathrm{K})}
\end{aligned}
$$

Eqn (40) and (41) apply in the ranges $0.790 \leq X_{\text {water }} \leq 1.000$ and $15.0 \leq T \leq 55.0^{\circ} \mathrm{C}$.

Fig. 4 shows a typical plot of $\ln \left(k_{\text {obs }}\right) v s$. $\varepsilon$. The non-linear regression analysis uses eqn (35) with $a=0$. Table 4 shows values for $\left(\frac{\partial \varepsilon}{\partial X}\right)_{T}$ and $b$, and the applicable relative permittivity 


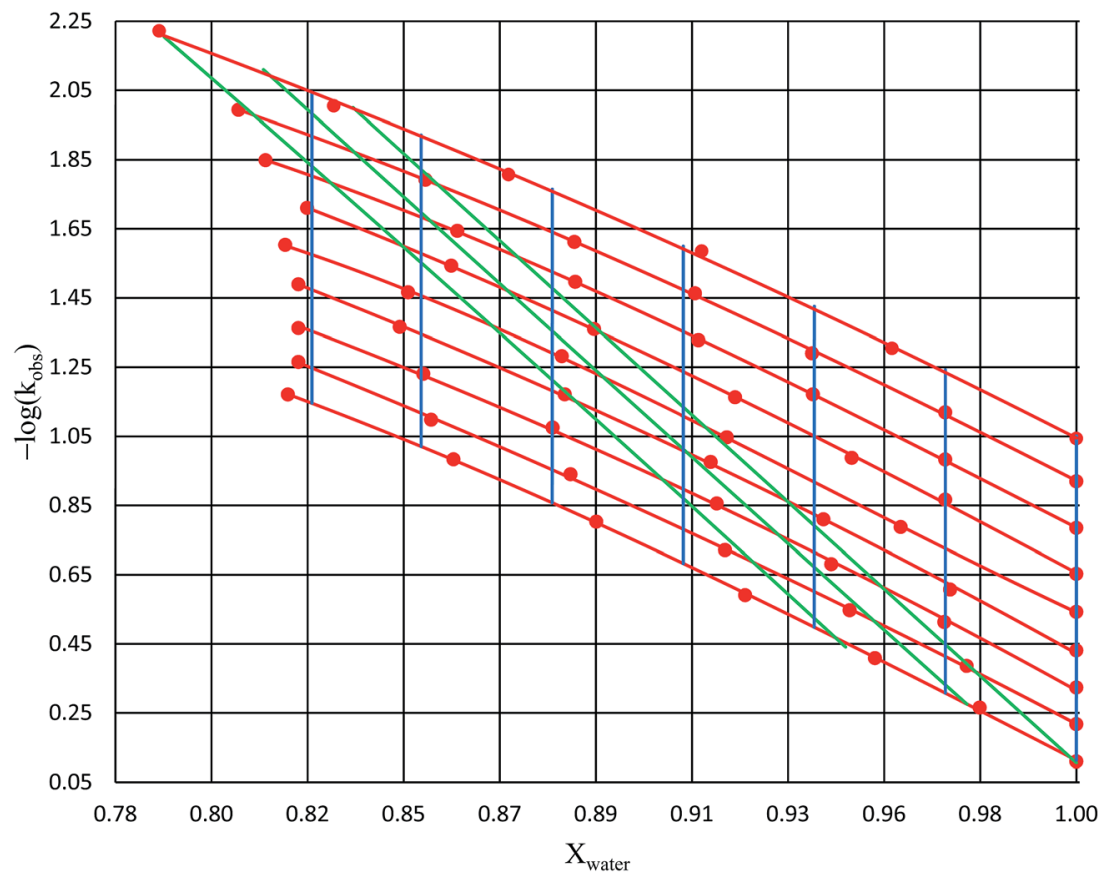

Fig. 2 Plots of $-\log \left(k_{\text {obs }}\right)$ vs. $X_{\text {water }}$ for acetic anhydride hydrolysis in the acetonitrile/water cosolvent system. The solid red circles are the observed rate constants in $\mathrm{min}^{-1}$. The red lines represent isotherms (from top to bottom: $15.0{ }^{\circ} \mathrm{C}, 20.0^{\circ} \mathrm{C}, 25.0^{\circ} \mathrm{C}, 30.0^{\circ} \mathrm{C}, 35.0^{\circ} \mathrm{C}, 40.0^{\circ} \mathrm{C}$, $45.0^{\circ} \mathrm{C}, 50.0^{\circ} \mathrm{C}$, and $55.0^{\circ} \mathrm{C}$ ); the green lines represent isodielectric lines (from right to left: $68.33,66.62$, and 64.72 ); and the blue lines represent iso-mole fraction lines (from right to left: $1.000,0.970,0.940,0.910,0.880,0.850$, and 0.825). All points are at least triplicate (generally more), and the average percent error on the standard deviations is $1.7 \%$.

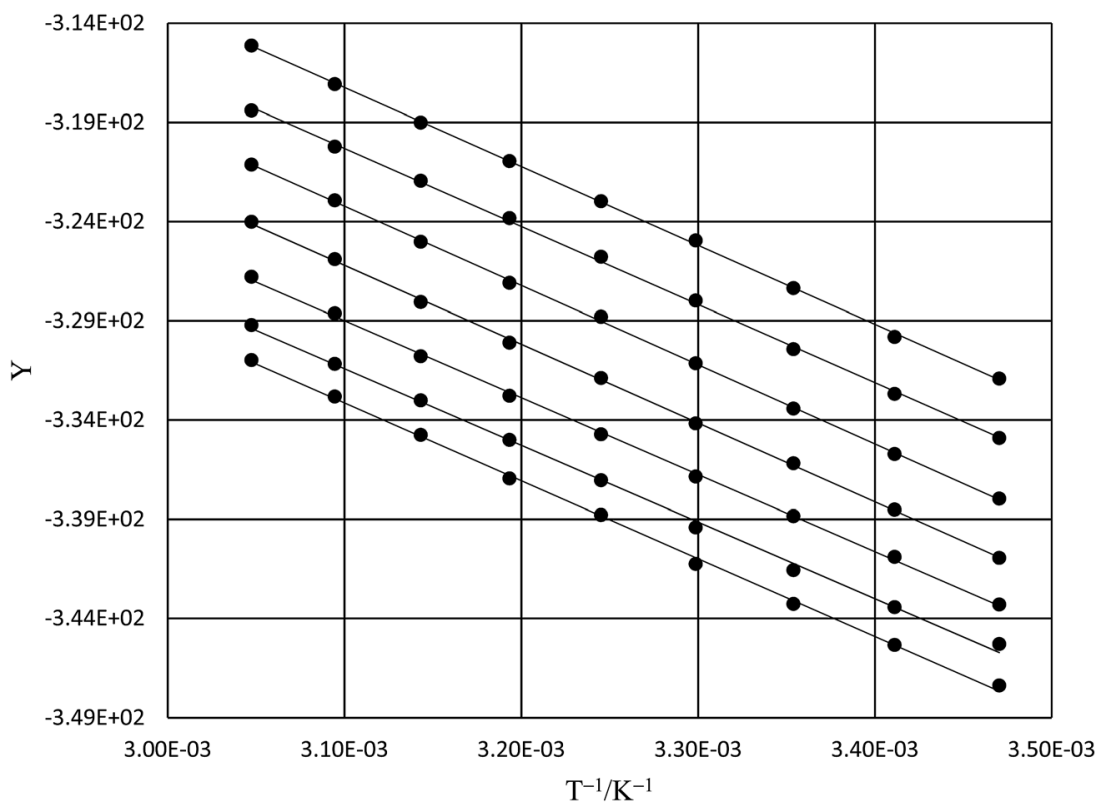

Fig. 3 Iso-mole fraction Eyring plots and the regression analyses using eqn (37). The water mole fractions from top to bottom are: $1.000,0.970$, $0.940,0.910,0.880,0.850$, and 0.825 . The points for mole fraction 1.000 are measured data; all other points are calculated from regression polynomials. The correlation coefficients range from 0.9990 to 0.9999 . 
Table 2 Activation parameters from the linear regression analyses under iso-mole fraction conditions using eqn (37). Errors are shown in parentheses. The activation free energies are calculated for $25.0^{\circ} \mathrm{C}$

\begin{tabular}{llll}
\hline$X_{\text {water }}$ & $\Delta H^{\ddagger} / \mathrm{kJ} \mathrm{mol}^{-1}$ & $\Delta S^{\ddagger} / \mathrm{J} \mathrm{K}^{-1} \mathrm{~mol}^{-1}$ & $\Delta G^{\ddagger} / \mathrm{kJ} \mathrm{mol}^{-1}$ \\
\hline 1.000 & $39.80( \pm 0.25)$ & $-193.9( \pm 0.8)$ & $97.6( \pm 0.8)$ \\
0.970 & $38.39( \pm 0.39)$ & $-198.2( \pm 1.3)$ & $97.5( \pm 1.4)$ \\
0.940 & $40.03( \pm 0.29)$ & $-199.1( \pm 0.9)$ & $99.4( \pm 0.9)$ \\
0.910 & $39.80( \pm 0.33)$ & $-202.9( \pm 1.1)$ & $100( \pm 1)$ \\
0.880 & $38.86( \pm 0.40)$ & $-208.5( \pm 1.3)$ & $101( \pm 1)$ \\
0.850 & $38.66( \pm 0.61)$ & $-211.6( \pm 2.0)$ & $102( \pm 2)$ \\
0.825 & $38.23( \pm 0.50)$ & $-211.5( \pm 1.6)$ & $101( \pm 2)$
\end{tabular}

Table 3 Values for $\left(\frac{\partial \varepsilon}{\partial T}\right)_{X}$ for the acetonitrile/water system at various water mole fractions. The relative permittivity range is 53.08 to 80.16 , and the temperature range is 15.0 to $55.0^{\circ} \mathrm{C}$. The data used for the analyses is from ref. 33

\begin{tabular}{ll}
\hline$X_{\text {water }}$ & $\left(\frac{\partial \varepsilon}{\partial T}\right)_{X} / \mathrm{K}^{-1}$ \\
\hline 1.0000 & -0.342 \\
0.9535 & -0.330 \\
0.9012 & -0.307 \\
0.8420 & -0.286 \\
0.7740 & -0.260
\end{tabular}

range at each temperature. A linear fit of $\left(\frac{\partial \varepsilon}{\partial X}\right)_{T}$ vs. T yields:

$$
\left(\frac{\partial \varepsilon}{\partial X}\right)_{T}=190-(0.370)(T / \mathrm{K})
$$

Table 4 Values for $\left(\frac{\partial \varepsilon}{\partial X}\right)_{T}, b$ (from the non-linear regression analysis of eqn (35) with $a=0$ ), and the applicable relative permittivity ranges at various temperatures for acetic anhydride hydrolysis in the acetonitrile/water system. The data used to analyze the values for $\left(\frac{\partial \varepsilon}{\partial X}\right)_{T}$ is in ref. 33

\begin{tabular}{llll}
\hline & $\left(\frac{\partial \varepsilon}{\partial X}\right)_{T}$ & $-10^{3} \mathrm{~b} / \mathrm{kJ} \mathrm{mol}^{-1}$ & $\begin{array}{l}\text { Relative permittivity } \\
\text { range }\end{array}$ \\
\hline 15.0 & $83.5( \pm 1.6)$ & $5.01( \pm 0.07)$ & $64.6-81.2$ \\
20.0 & $81.4( \pm 1.4)$ & $5.34( \pm 0.07)$ & $64.7-80.3$ \\
25.0 & $79.5( \pm 1.0)$ & $5.82( \pm 0.08)$ & $63.6-78.4$ \\
30.0 & $77.6( \pm 1.4)$ & $6.39( \pm 0.04)$ & $63.0-76.7$ \\
35.0 & $75.0( \pm 1.1)$ & $6.85( \pm 0.09)$ & $61.3-74.9$ \\
40.0 & $73.6( \pm 1.5)$ & $7.28( \pm 0.10)$ & $60.1-73.2$ \\
45.0 & $72.2( \pm 1.3)$ & $7.65( \pm 0.11)$ & $58.7-71.6$ \\
50.0 & $70.6( \pm 1.0)$ & $8.03( \pm 0.09)$ & $57.4-70.0$ \\
55.0 & $68.3( \pm 1.3)$ & $8.73( \pm 0.08)$ & $56.0-68.3$
\end{tabular}

Using eqn (27), (28), (39), and (42), the expressions for $\left(\frac{\partial \Delta H^{\ddagger}}{\partial X}\right)_{\varepsilon, T}$ and $\left(\frac{\partial \Delta S^{\ddagger}}{\partial X}\right)_{\varepsilon, T}$ become:

$$
\left(\frac{\partial \Delta H^{\ddagger}}{\partial X}\right)_{\varepsilon, T}=\left(\frac{\partial \Delta H^{\ddagger}}{\partial X}\right)_{T}-\frac{\Delta C_{\mathrm{p}}^{\ddagger}[190-(0.370)(T / K)]}{\left(0.371 \mathrm{~K}^{-1}\right) X_{\text {water }}-0.027 \mathrm{~K}^{-1}}
$$

$$
\left(\frac{\partial \Delta S^{\ddagger}}{\partial X}\right)_{\varepsilon, T}=\left(\frac{\partial \Delta S^{\ddagger}}{\partial X}\right)_{T}-\frac{\Delta C_{\mathrm{p}}^{\ddagger}[190-(0.370)(T / \mathrm{K})]}{\left[(0.371) X_{\text {water }}-0.027\right](T / \mathrm{K})}
$$

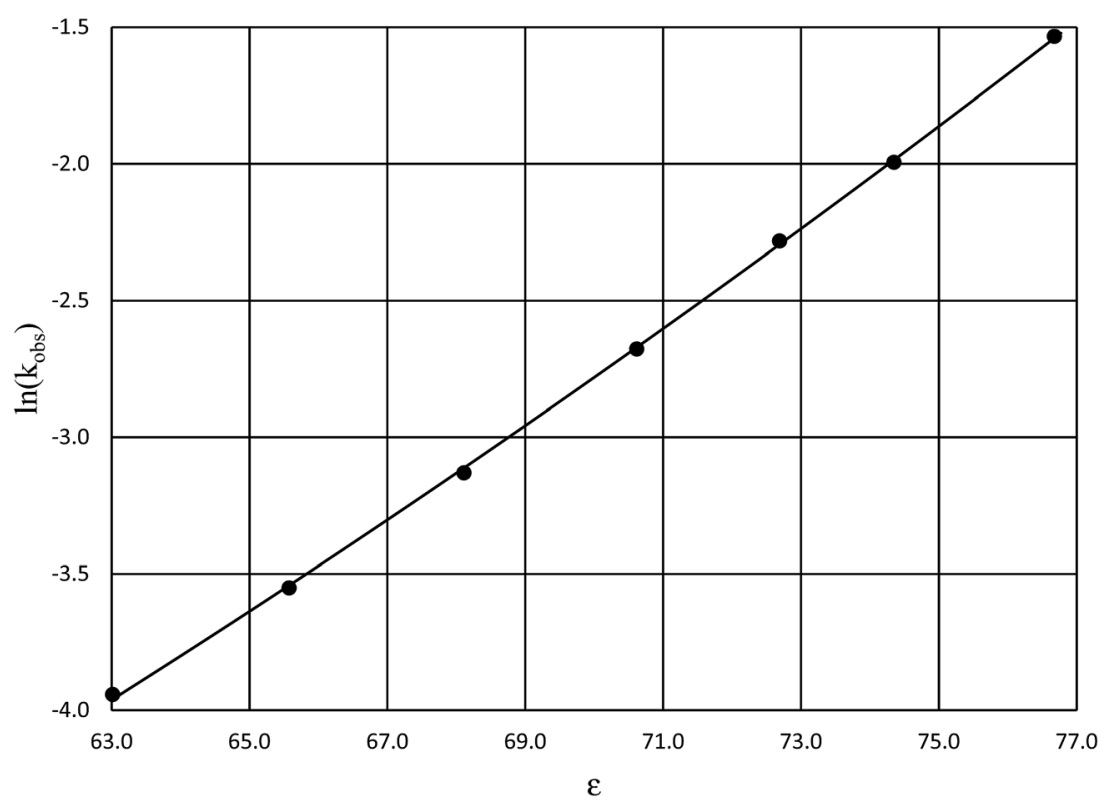

Fig. 4 Plot of $\ln \left(k_{\text {obs }}\right)$ vs. $\varepsilon$ for acetic anhydride hydrolysis in the acetonitrile/water cosolvent system at $30.0^{\circ} \mathrm{C}$. The non-linear regression curve is generated using eqn (35) with $a=0$. The water mole fraction range for the data presented here is 0.824 to 1.000 , and the regression correlation coefficient is 0.9999 . 


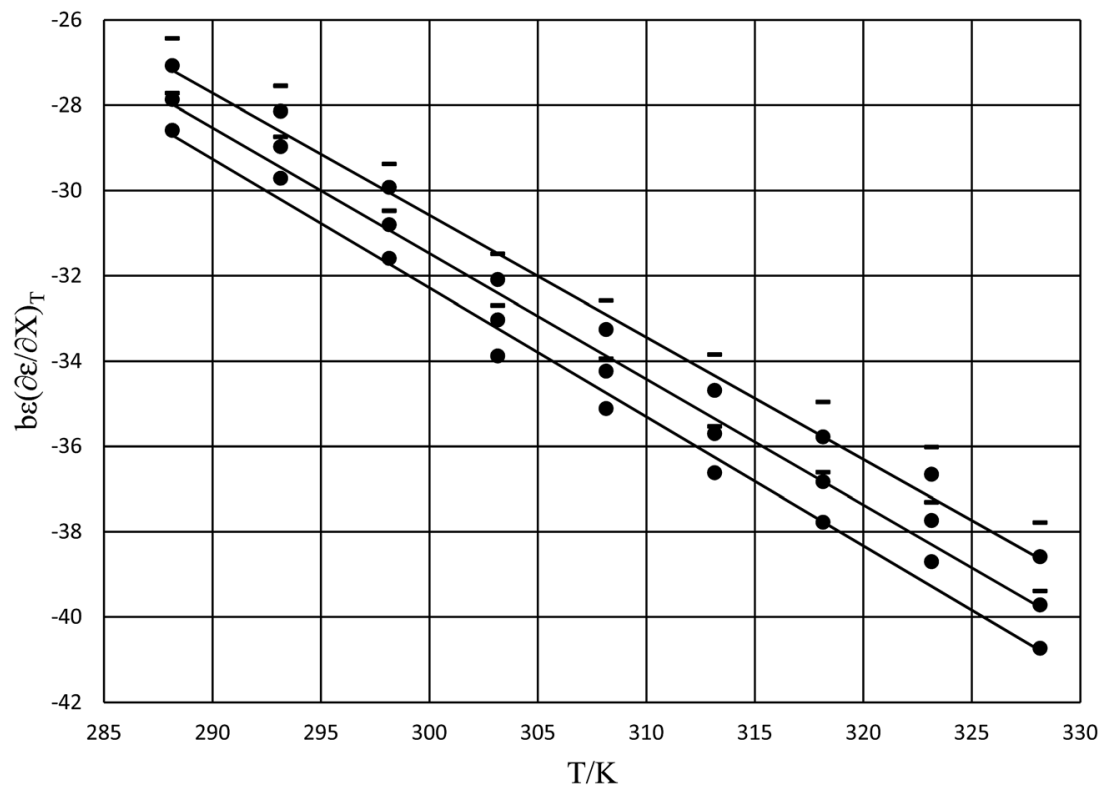

Fig. 5 Plots of $b \varepsilon\left(\frac{\partial \varepsilon}{\partial X}\right)_{T}$ vs. $T$ and the linear regression lines for the following relative permittivities: 64.72 (top curve), 66.62 (middle curve), and 68.33 (bottom curve). The errors bars are shown for the top curve only. The correlation coefficients are all 0.995.

Eqn (43) and (44) apply in the ranges $0.790 \leq X_{\text {water }} \leq 1.000$ and $15.0 \leq T \leq 55.0{ }^{\circ} \mathrm{C}$.

As evident in Fig. 2, the isodielectric lines span a rather wide swath, so only a narrow relative permittivity range can be used. Relative permittivity values of $68.33,66.62$, and 64.72 have been chosen for the analysis.

The rate constants and water concentrations are calculated from regression polynomials generated for each of these relative permittivities. Fig. 5 shows the linear regression analyses of eqn (12) using the data in Table 4 for the three relative permittivities, and Table 5 shows the regression values for $\left(\frac{\partial \Delta H^{\ddagger}}{\partial X}\right)_{T}$ and $\left(\frac{\partial \Delta S^{\ddagger}}{\partial X}\right)_{T}$. It is noted here that $\left(\frac{\partial \Delta G^{\ddagger}}{\partial \varepsilon}\right)_{T}=b \varepsilon$ as indicated in eqn (33).

Table 6 shows regression values for $a_{\varepsilon}, b_{\varepsilon}$, and $\left(\frac{\partial X}{\partial T}\right)_{\varepsilon}$ for the three relative permittivities. Fig. 6 shows the isodielectric plots and the non-linear regression analyses of eqn (38) for the three relative permittivities. $\Delta H_{\mathrm{r}}^{\ddagger}$ and $\Delta S_{\mathrm{r}}^{\ddagger}$ are the only adjustable parameters in the analyses, and the regression coefficients are independent of the value for $T_{\mathrm{r}}$. Table 7 shows the activation parameters from the regression analyses for the three relative permittivities and $T_{\mathrm{r}}=15.0$ and $55.0{ }^{\circ} \mathrm{C}$.

\section{Linear solvent energy relations}

The Kamlet-Taft free energy relationship for solvent effects is: ${ }^{4-7}$

$$
\log \frac{k_{x}}{k_{1}}=s \pi^{*}+a \alpha+b \beta
$$

in which $k_{1}$ is the rate constant at a water mole fraction of 1.000 , $\pi^{*}$ is the solvent polarity/polarizability parameter, $\alpha$ is the
Table 5 Regression values for $\left(\frac{\partial \Delta H^{\ddagger}}{\partial X}\right)_{T}$ and $\left(\frac{\partial \Delta S^{\ddagger}}{\partial X}\right)_{T}$ at the three
relative permittivities

\begin{tabular}{lll}
$\varepsilon$ & $\left(\frac{\partial \Delta H^{\ddagger}}{\partial X}\right)_{T} / \mathrm{kJ} \mathrm{mol}^{-1}$ & $\left(\frac{\partial \Delta S^{\ddagger}}{\partial X}\right)_{T} / \mathrm{J} \mathrm{K}^{-1} \mathrm{~mol}^{-1}$ \\
\hline 64.72 & $55.3( \pm 3.3)$ & $286( \pm 11)$ \\
66.62 & $57.0( \pm 3.3)$ & $295( \pm 11)$ \\
68.33 & $58.4( \pm 3.3)$ & $302( \pm 11)$
\end{tabular}

Table 6 Values for $a_{\varepsilon}$ and $b_{\varepsilon}$ and the expressions for $\left(\frac{\partial X}{\partial T}\right)_{\varepsilon}$ at the three relative permittivities. The temperature range is 15.0 to $55.0^{\circ} \mathrm{C}$, and the water mole fraction range is 0.779 to 1.000 . The data used for the analyses is from regression polynomials

\begin{tabular}{llll}
$\varepsilon$ & $a_{\varepsilon} / \mathrm{K}^{-2}$ & $b_{\varepsilon} / \mathrm{K}^{-1}$ & $\left(\frac{\partial X}{\partial T}\right)_{\varepsilon}$ \\
\hline 68.33 & $1.202 \times 10^{-5}$ & -0.003305 & $\left(2.404 \times 10^{-5} \mathrm{~K}^{-2}\right) T-0.003305 \mathrm{~K}^{-1}$ \\
66.62 & $1.179 \times 10^{-5}$ & -0.003269 & $\left(2.358 \times 10^{-5} \mathrm{~K}^{-2}\right) T-0.003269 \mathrm{~K}^{-1}$ \\
64.72 & $1.186 \times 10^{-5}$ & -0.003437 & $\left(2.372 \times 10^{-5} \mathrm{~K}^{-2}\right) T-0.003437 \mathrm{~K}^{-1}$
\end{tabular}

solvent hydrogen bond donating (HBD) parameter, $\beta$ is the hydrogen bond accepting (HBA) parameter, and $s, a$, and $b$ are the corresponding solvatochromic coefficients that quantify the relative contributions from each of these solvatochromic effects. These solvent parameters have been characterized for the equilibria of quinolone antibacterials in acetonitrile/water mixtures at $25{ }^{\circ} \mathrm{C} .{ }^{34}$ Plots of these parameters vs. the water mole fraction, along with the polynomial fits, are shown in Fig. 7. The plot of $\log \frac{k_{x}}{k_{1}}$ vs. $X_{\text {water }}$ and the regression analysis 


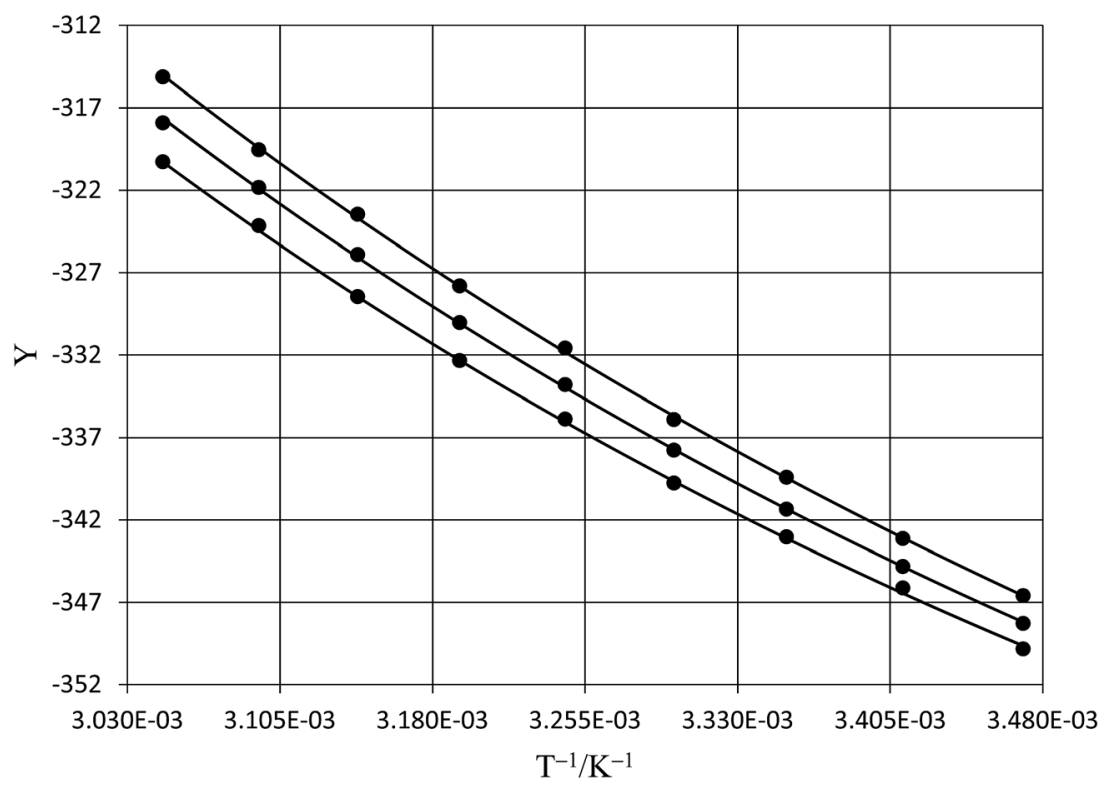

Fig. 6 Isodielectric Eyring plots and non-linear regression analyses using eqn (38). The relative permittivities are: 68.33 (top curve), 66.62 (middle curve), and 64.72 (bottom curve). The water mole fraction range is 0.790 to 1.000. All data points are calculated from regression polynomials. The correlation coefficients are all 0.9999.

Table 7 Isodielectric activation parameters from the non-linear regression analyses of eqn (38) for the three relative permittivities and $T_{\mathrm{r}}=15.0$ and $55.0^{\circ} \mathrm{C}$

\begin{tabular}{lllll}
\hline$\varepsilon$ & $T_{\mathrm{r}} /{ }^{\circ} \mathrm{C}$ & $\Delta H_{\mathrm{r}}^{\ddagger} / \mathrm{kJ} \mathrm{mol}^{-1}$ & $\Delta S_{\mathrm{r}}^{\ddagger} / \mathrm{J} \mathrm{K}^{-1} \mathrm{~mol}^{-1}$ & $\Delta G_{\mathrm{r}}^{\ddagger} / \mathrm{kJ} \mathrm{mol}^{-1}$ \\
\hline 68.33 & 15.0 & $28.93( \pm 0.40)$ & $-246.2( \pm 1.3)$ & $99.9( \pm 1.4)$ \\
& 55.0 & $38.01( \pm 0.40)$ & $-199.2( \pm 1.3)$ & $103.4( \pm 1.4)$ \\
66.62 & 15.0 & $26.43( \pm 0.36)$ & $-256.5( \pm 1.2)$ & $100.4( \pm 1.3)$ \\
& 55.0 & $35.53( \pm 0.36)$ & $-209.3( \pm 1.2)$ & $104.2( \pm 1.3)$ \\
64.72 & 15.0 & $23.89( \pm 0.43)$ & $-266.7( \pm 1.4)$ & $100.7( \pm 1.5)$ \\
& 55.0 & $32.94( \pm 0.43)$ & $-219.9( \pm 1.4)$ & $105.1( \pm 1.5)$
\end{tabular}

using eqn (45) with these polynomial functions are shown in Fig. 8. Regression analysis yields the following results for the solvatochromic coefficients: $s=7.19$ (0.09), $a=-1.66$ (0.07), and $b=-10.93(0.06)$. The correlation coefficient is 0.99998 .

\section{Discussion}

Comparison of the computational data in Table 1 with the thermodynamic data in Table 2 reveals excellent agreement for the activation enthalpy for transition state B. None of the other transition states are even close in agreement. However, the data in Table 7 shows a temperature variability of the thermodynamic parameters, making comparison with a single set of theoretical values tenuous. The computational activation entropy is low, but the analysis of the experimental data indicates there is a significant solvent effect upon the activation entropy. As will be discussed, this effect likely represents a close-range molecular interaction that is not captured by the computational methods. Nonetheless, the close agreement of the numeric values of the activation enthalpy, coupled with the low activation free energy for transition state B, argues strongly against the other transitions states being viable options.

The data in Table 2 shows that the activation entropy for simple acetic anhydride hydrolysis under iso-mole fraction conditions contributes about $60 \%$ of the activation free energy at $25{ }^{\circ} \mathrm{C}$. The contribution from the activation entropy is notably different for other reactions conducted in cosolvent systems, such as the amine-catalyzed ring opening of azlactones, ${ }^{35-38}$ and the hydrolyses of some metal complexes. ${ }^{39-41}$ The contribution from the activation entropies for metal complex hydrolyses is much lower than for simple acetic anhydride hydrolysis. Metal complex hydrolyses exhibit non-zero values for $\left(\frac{\partial \Delta H^{\ddagger}}{\partial X}\right)_{T}$ and $\left(\frac{\partial \Delta S^{\ddagger}}{\partial X}\right)_{T}$, but values near zero for $\left(\frac{\partial \Delta G^{*}}{\partial X}\right)_{T}$. The azlactone ring opening reactions, on the other hand, have contributions from the activation entropies that are higher than for simple acetic anhydride hydrolysis. The values for $\left(\frac{\partial \Delta H^{\ddagger}}{\partial X}\right)_{T},\left(\frac{\partial \Delta S^{\ddagger}}{\partial X}\right)_{T}$, and $\left(\frac{\partial \Delta G^{*}}{\partial X}\right)_{T}$ are all non-zero for these reactions. The emerging trend seems to be that reactions with larger contributions from the activation entropy tend to exhibit non-zero values for $\left(\frac{\partial \Delta G^{*}}{\partial X}\right)_{T}$, whereas reactions with larger contributions from the activation enthalpy tend to exhibit values for $\left(\frac{\partial \Delta G^{\star}}{\partial X}\right)_{T}$ that are close to zero.

Table 8 shows values for the double constraint differential terms calculated for $25{ }^{\circ} \mathrm{C}$, a water mole fraction of 0.901 , and a relative permittivity of 66.62 (These values are arbitrarily chosen for the sake of discussion.). The value for $\Delta C_{\mathrm{p}}^{\ddagger}$ used to 


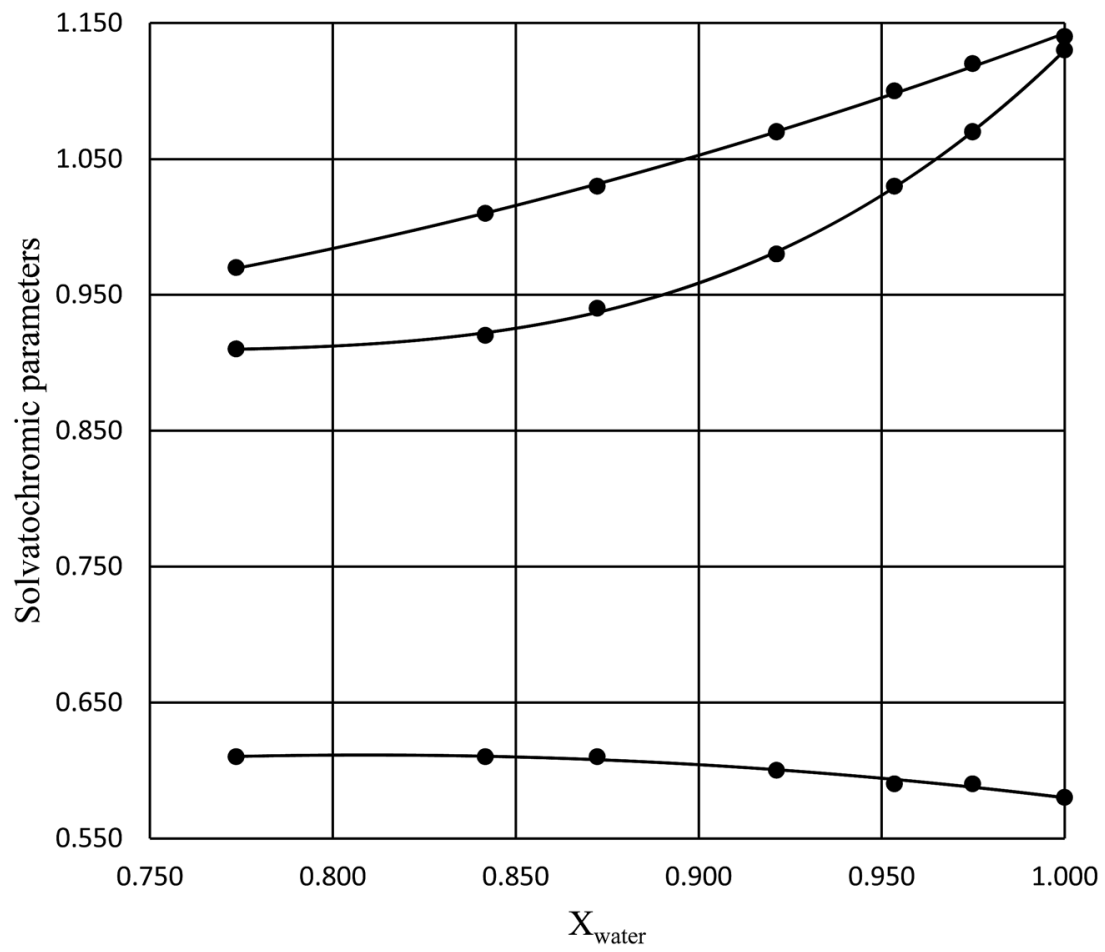

Fig. 7 Plots of $\pi^{*}$ (top curve), $\alpha$ (middle curve), and $\beta$ (bottom curve) vs. $X_{\text {water, }}$ and the corresponding polynomial fits. The data is for $25^{\circ} \mathrm{C}$, and is from ref. 34

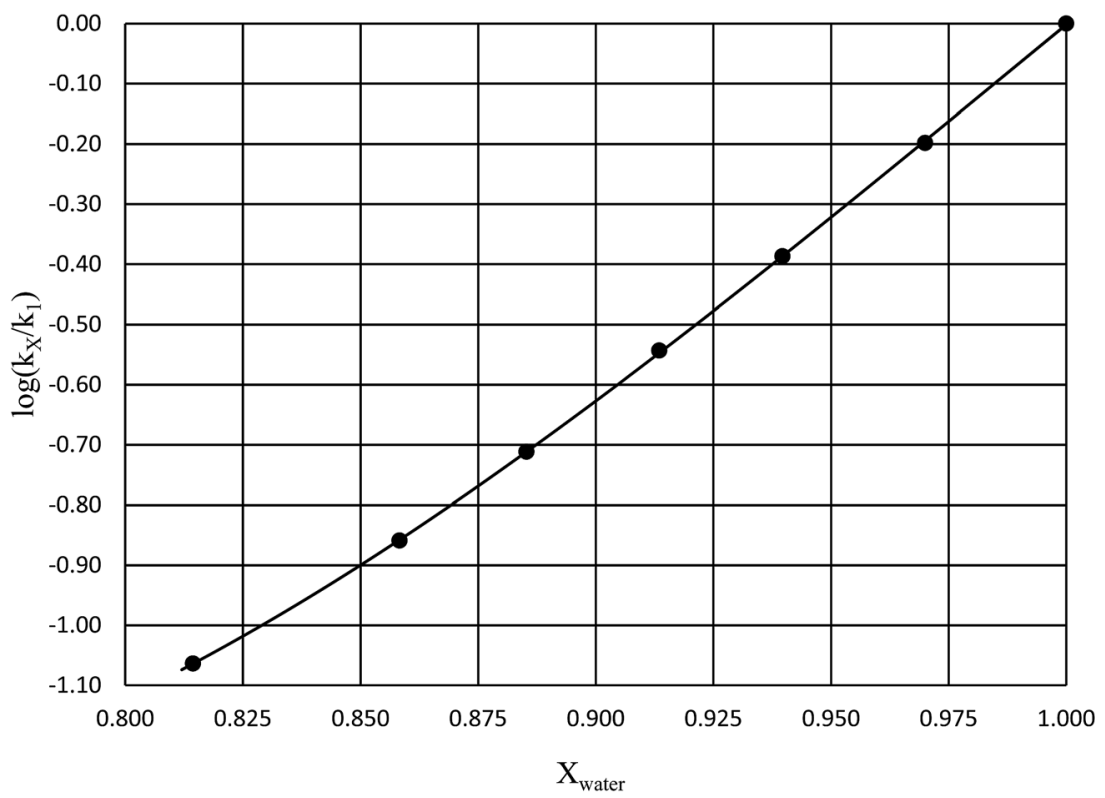

Fig. 8 Plot of $\log \frac{k_{x}}{k_{1}}$ vs. $X_{\text {water }}$ and the regression analysis using eqn (45).

calculate these terms has been estimated from the following expression: ${ }^{25}$

$$
\Delta C_{\mathrm{p}}^{\ddagger}=-3 m R+C_{\mathrm{p}, \mathrm{vib}}^{\ddagger}-\sum C_{\mathrm{p}, \mathrm{vib}}+C_{\mathrm{p}, \mathrm{sol}}^{\ddagger}-C_{\mathrm{p}, \mathrm{sol}}
$$

In this equation, the first right-hand-side term is the difference in the translational and rotational heat capacities between the transition and reactant states, $m$ is the water molecularity, $C_{\mathrm{p}, \text { vib }}^{\sharp}$ is the transition-state vibrational heat capacity, $\sum C_{\mathrm{p} \text {,vib }}$ is the sum of the reactant-state vibrational heat capacities, and $C_{\mathrm{p}, \mathrm{sol}}^{*}$ and $C_{\mathrm{p}, \mathrm{sol}}$ are the heat capacity contributions from the intermolecular interactions between the solvent shell and the transition and reactant states, respectively. $\Delta C_{\mathrm{p}}^{\ddagger}$ is approximately $-24.9 \mathrm{~J} \mathrm{~K}^{-1} \mathrm{~mol}^{-1}$ for $m=1$ if $-3 m R$ is the dominant term. 
Table 8 Values for the double constraint differential terms for acetic anhydride hydrolysis in the acetonitrile/water system at $25^{\circ} \mathrm{C}$, a water mole fraction of 0.901 , and a relative permittivity of 66.62

Thermodynamic

term

Value for the term

$$
\begin{aligned}
& \left(\frac{\partial \Delta H^{\ddagger}}{\partial \varepsilon}\right)_{X, T} \\
& \left(\frac{\partial \Delta S^{\ddagger}}{\partial \varepsilon}\right)_{X, T} \\
& \left(\frac{\partial \Delta G^{\ddagger}}{\partial \varepsilon}\right)_{X, T} \\
& \left(\frac{\partial \Delta H^{\ddagger}}{\partial X}\right)_{\varepsilon, T} \\
& \left(\frac{\partial \Delta S^{\ddagger}}{\partial \mathrm{X}}\right)_{\varepsilon, \mathrm{T}} \\
& \left(\frac{\partial \Delta G^{\ddagger}}{\partial X}\right)_{\varepsilon, T}
\end{aligned}
$$

$63.5 \mathrm{~kJ} \mathrm{~mol}^{-1}$

$317 \mathrm{~J} \mathrm{~K}^{-1} \mathrm{~mol}^{-1}$

$-31.0 \mathrm{~kJ} \mathrm{~mol}^{-1}$ $\left(\frac{\partial \Delta S^{\ddagger}}{\partial X}\right)_{\varepsilon, T}$ dominates $\left(\frac{\partial \Delta H^{\ddagger}}{\partial X}\right)_{\varepsilon, T}$, making $\left(\frac{\partial \Delta G^{\ddagger}}{\partial X}\right)_{\varepsilon, T}$ negative. The overall effect is the transition state becomes thermodynamically destabilized at higher acetonitrile mole fractions under isothermal and isodielectric conditions.

The data analyzed using the Kamlet-Taft equation (eqn (45)) is for isothermal and variable mole fraction conditions, and hence the isothermal differential terms in Table 5 can be correlated with the LSER results. The differential terms for the response to each solvatochromic parameter are derived from eqn (45) as follows:

The positive value for $\left(\frac{\partial \Delta H^{*}}{\partial X}\right)_{\varepsilon, T}$ indicates that an increase in the water mole fraction under isodielectric and isothermal conditions energetically destabilizes the transition state. The negative value for $\left(\frac{\partial \Delta H^{*}}{\partial \varepsilon}\right)_{X, T}$, on the other hand, indicates that an increase in the relative permittivity under iso-mole fraction and isothermal conditions energetically stabilizes the transition state. Since an increase in the solvent relative permittivity decreases the activation enthalpy if there is charge development in the transition state, ${ }^{\mathbf{1 1 - 1 3}}$ a negative value for $\left(\frac{\partial \Delta H^{\ddagger}}{\partial \varepsilon}\right)_{X, T}$ indicates charge development in the transition state. However, the small numeric value for this term indicates either the charge development is not very large, or the dipole moment of the transition state is not large. This result is consistent with the computational results, which indicate some degree of charge development for all the transition states studied, and a relatively small dipole moment for transition state B.

A significant hydrogen bond accepting/donating (HBA/HBD) interaction is expected to occur between the lone pairs on the composite solvent structure and the non-transferring hydrogen atom on the nucleophilic water molecule. The fact that $\left(\frac{\partial \Delta H^{\ddagger}}{\partial X}\right)_{\varepsilon, T}$ is positive implies this interaction is stronger in the cosolvent mixture than in pure water. This is consistent with solvent characterization studies that show the solution basicity rises sharply when the acetonitrile mole fraction changes from 0.0 to 0.3 in aqueous solutions. ${ }^{42}$ Various spectroscopic data ${ }^{43-49}$ also reveal significant solvent structural changes when acetonitrile is added to water. The positive value for $\left(\frac{\partial \Delta S^{\ddagger}}{\partial X}\right)_{\varepsilon, T}$ likely indicates a tightening of the HBA/HBD solvent structure around the transition state at higher acetonitrile mole fractions, which is consistent with $\left(\frac{\partial \Delta H^{\ddagger}}{\partial X}\right)_{\varepsilon, T}$ being positive. Not surprisingly,

$$
\begin{aligned}
& {\left[\frac{\partial \log \left(\frac{k_{x}}{k_{1}}\right)}{\partial X}\right]_{\pi^{*}, \alpha}=b\left(\frac{\mathrm{d} \beta}{\mathrm{d} X}\right)} \\
& {\left[\frac{\partial \log \left(\frac{k_{x}}{k_{1}}\right)}{\partial X}\right]_{\pi^{*}, \beta}=a\left(\frac{\mathrm{d} \alpha}{\mathrm{d} X}\right)} \\
& {\left[\frac{\partial \log \left(\frac{k_{x}}{k_{1}}\right)}{\partial X}\right]_{\alpha, \beta}=s\left(\frac{\mathrm{d} \pi^{*}}{\mathrm{~d} X}\right)}
\end{aligned}
$$

Fig. 7 shows that $\frac{\mathrm{d} \beta}{\mathrm{d} X}$ is negative. Since $b$ is also negative; $\left[\frac{\partial \log \left(\frac{k_{x}}{k_{1}}\right)}{\partial X}\right]_{\pi^{*}, \alpha}$ is positive, which implies that the HBA capability of the cosolvent system, which is stronger at higher acetonitrile mole fractions, stabilizes the reactant state more than the transition state. This is consistent with the thermodynamic results, but as discussed in the previous paragraph, this effect is largely entropic. Fig. 7 shows that $\frac{\mathrm{d} \pi^{*}}{\mathrm{~d} X}$ is positive. Since $s$ is also positive; $\left[\frac{\partial \log \left(\frac{k_{x}}{k_{1}}\right)}{\partial X}\right]_{\alpha, \beta}$ is positive, which implies that the effect of solvent polarity/polarizability is stronger at higher water mole fractions. This is undoubtedly due to the stabilizing effect of higher relative permittivity on the transition state. Fig. 7 shows that $\frac{\mathrm{d} \alpha}{\mathrm{d} X}$ is positive at water mole fractions above $\sim 0.85$, and approximately zero below 0.85 . Therefore, since $a$ is negative; $\left[\frac{\partial \log \left(\frac{k_{x}}{k_{1}}\right)}{\partial X}\right]_{\pi^{*}, \beta}$ is also negative above 0.85 . This implies that the HBD capability of the cosolvent system, which is stronger at higher water mole fractions, stabilizes the reactant state more than the transition state. This is likely due to the nucleophilic water molecule being more strongly hydrogen bonded in the reactant state than in the transition state.

\section{Conclusion}

The work presented in this article shows the type of information tractable using a conventional thermodynamic analysis of the 
activation parameters in the Eyring equation. Aside from the shortcomings of applying the Eyring theory to faster solutionphase reactions, the only limitation is the terms used in the analysis must be measurable quantities such as temperature, mole fraction, relative permittivity, dipole moment, and refractive index. Specific solvent-solute interactions, while they certainly affect reaction rates, are not directly measurable quantities. However, as demonstrated in this work they can be inferred through specific thermodynamic terms, such as those shown in Table 8. Thermodynamics is an exact science, so within the limitations of applying Eyring rate theory to solution kinetics, the results presented in this work are exact. As such, the thermodynamic analysis, although not so much a predictive tool, nonetheless serves a valuable complement to empirical techniques such as LSERs. The unique benefit to the thermodynamic analysis is the activation enthalpy and entropy can be analyzed as separate terms, and under specific conditions. This level of detail allows the inference of more structural details of the transition state than is possible with LSERs or with a traditional interpretation of the Eyring plots.

To the authors' knowledge the approach presented in this article is novel, and the hope is that more research will be conducted in this area. Work is currently underway in the authors' laboratories to study simple acetic anhydride hydrolysis in other cosolvent systems such as acetone/water, tetrahydrofuran/water, dioxane/water, and alcohols/water. The intent is to uncover a trend in the thermodynamic terms, and to develop general structural inferences by expanding the database. In addition, work is underway to incorporate appropriate thermodynamic terms into the traditional expressions that relate the rate constant to the relative permittivity. The intent here is to better quantify the effects of relative permittivity, and better explain why experimental data often does not conform to the functional forms of these longstanding expressions.

\section{References}

1 C. Reichardt and T. Welton, Solvent and Solvent Effects in Organic Chemistry, Wiley-VCH, 4th edn, 2011.

2 E. Grunwald and S. Winstein, J. Am. Chem. Soc., 1948, 70, 846-854.

3 S. Winstein, E. Grunwald and H. W. Jones, J. Am. Chem. Soc., 1951, 73, 2700-2707.

4 M. J. Kamlet and R. W. Taft, J. Am. Chem. Soc., 1976, 98, 377383.

5 M. J. Kamlet, J. L. Abboud and R. W. Taft, J. Am. Chem. Soc., 1977, 99, 6027-6038.

6 M. J. Kamlet and R. W. Taft, J. Chem. Soc., Perkin Trans. 2, 1979, 337-341.

7 M. J. Kamlet, J. L. Abboud, M. H. Abraham and R. W. Taft, J. Org. Chem., 1983, 48, 2877-2887.

8 M. Sjostrom and S. Wold, Acta Chem. Scand., Ser. B, 1981, 35, 537-554.

9 E. Eyring, J. Chem. Phys., 1935, 3, 107-115.

10 M. G. Evans and M. Polanyi, Trans. Faraday Soc., 1935, 31, 875-894.
11 E. D. Hughes and C. K. Ingold, Trans. Faraday Soc., 1941, 37, 657-685.

12 C. K. Ingold, Structure and Mechanisms in Organic Chemistry, Cornell University Press, Ithaca/New York and London, 2nd edn, 1969.

13 E. D. Hughes and C. K. Ingold, J. Chem. Soc., 1935, 244-255.

14 K. A. Cooper, M. L. Dhar, E. D. Hughes, C. K. Ingold, B. J. MacNulty and L. I. Woolf, J. Chem. Soc., 1948, 20432049.

15 J. G. Kirkwood, J. Chem. Phys., 1934, 2, 351-361.

16 E. S. Amis, Solvent Effects on Reaction Rates and Mechanisms, Academic Press, New York and London, 1966.

17 E. S. Amis and J. F. Hinton, Solvent Effects on Chemical Phenomena, Academic Press, New York and London, 1973, vol. 1.

18 K. L. Laidler, Chemical Kinetics, Harper and Row, Hilversum, 3rd edn, 1987.

19 K. L. Laidler and P. A. Landskroener, Trans. Faraday Soc., 1956, 52, 200-210.

20 D. G. Oakenfull, Aust. J. Chem., 1974, 27, 1423-1431.

21 R. E. Robertson, B. Rossall and A. Redmond, Can. J. Chem., 1971, 49, 3665-3670.

22 B. D. Batts and V. J. Gold, J. Chem. Soc. A, 1969, 984-987.

23 A. R. Butler and V. J. Gold, J. Chem. Soc., 1961, 2305-2312.

24 W. H. Hirota, R. B. Rodrigues, C. Sayer and R. do Giudici, Chem. Eng. Sci., 2010, 65(12), 3849-3858.

25 F. L. Wiseman, J. Phys. Org. Chem., 2012, 25, 1105-1111.

26 F. L. Wiseman, W. C. Cooper, C. Heishman and B. Robinson, Int. J. Adv. Res. Chem. Sci., 2015, 2(8), 1-9.

27 Y. Shao, L. F. Molnar, Y. Jung, J. Kussmann, C. Ochsenfeld, S. T. Brown, A. T. B. Gilbert, L. V. Slipchenko, S. V. Levchenko, D. P. O'Neill, R. A. DiStasio Jr, R. C. Lochan, T. Wang, G. J. O. Beran, N. A. Besley, J. M. Herbert, C. Y. Lin, T. Van Voorhis, S. H. Chien, A. Sodt, R. P. Steele, V. A. Rassolov, P. E. Maslen, P. P. Korambath, R. D. Adamson, B. Austin, J. Baker, E. F. C. Byrd, H. Dachsel, R. J. Doerksen, A. Dreuw, B. D. Dunietz, A. D. Dutoi, T. R. Furlani, S. R. Gwaltney, A. Heyden, S. Hirata, C.-P. Hsu, G. Kedziora, R. Z. Khalliulin, P. Klunzinger, A. M. Lee, M. S. Lee, W. Z. Liang, I. Lotan, N. Nair, B. Peters, E. I. Proynov, P. A. Pieniazek, Y. M. Rhee, J. Ritchie, E. Rosta, C. D. Sherrill, A. C. Simmonett, J. E. Subotnik, H. L. Woodcock III, W. Zhang, A. T. Bell, A. K. Chakraborty, D. M. Chipman, F. J. Keil, A. Warshel, W. J. Hehre, H. F. Schaefer, J. Kong, A. I. Krylov, P. M. W. Gill and M. Head-Gordon, Phys. Chem. Chem. Phys., 2006, 8, 3172-3191.

28 S. E. Wheeler, K. N. Houk, P. V. P. Schleyer and W. D. Allen, J. Am. Chem. Soc., 2009, 131, 2547-2560.

29 A. V. Marenich, R. M. Olsen, C. P. Kelly, C. J. Cramer and D. G. Truhlar, J. Chem. Theory Comput., 2007, 3, 2011-2033.

30 W. J. A. Hehre, A Guide to Molecular Mechanics and Quantum Chemical Calculations, Wavefunction, Inc., Irvine, CA, 2003, 299-304, pp. 717-732, and references cited therein.

31 O. A. El Seoud, R. C. Bazito and P. T. Sumodjo, J. Chem. Educ., 1997, 74(5), 562-565. 
32 B. Rossall and R. E. Robertson, Can. J. Chem., 1975, 53, 869877.

33 L. G. Gagliardi, C. B. Castells, C. Rafols, M. Roses and E. Bosch, J. Chem. Eng. Data, 2007, 52, 1103-1107.

34 J. Barbosa, R. Berges, I. Toro and V. Sanz-Nebet, Talanta, 1997, 44, 1271-1283.

35 A. M. Ismail and S. K. El-Sadany, Prog. React. Kinet. Mech., 2008, 33, 207-217.

36 A. M. Ismail, Indian J. Chem., Sect. A: Inorg., Bio-inorg., Phys., Theor. Anal. Chem., 2007, 46(06), 916-922.

37 D. J. Phelps, P. V. Gordreau and E. S. Nicholas, J. Chem. Soc., Perkin Trans. 2, 1981, 140-144.

38 N. A. Al-Jallal and A. M. Ismail, Asian J. Chem., 2011, 23(9), 3811-3814.

39 G. El-Subruiti, G. Younes and M. Jaber, Prog. React. Kinet. Mech., 2011, 36, 73-82.

40 G. El-Subruiti, K. Halawani and C. Wells, Transition Met. Chem., 1993, 18, 323-328.
41 M. Fathalla, G. El-Subruiti and Y. El-Marassi, Prog. React. Kinet. Mech., 2009, 34, 183-197.

42 J. Catalan, C. Diaz and F. Garcia-Blanco, Org. Biomol. Chem., 2003, 1, 575-580.

43 G. V. Kabisch, Z. Phys. Chem., 1982, 263, 48-60.

44 K. Kamogawa and T. Kitagawa, J. Phys. Chem., 1987, 91, 222226.

45 K. Rowlen and J. M. Harris, Anal. Chem., 1991, 63, 964-969. 46 B. Z. Gorbunov and Y. I. Naberukhin, Zh. Strukt. Khim., 1975, 16, 816-825.

47 D. Jamroz, J. Stangret and J. Lindgren, J. Am. Chem. Soc., 1993, 115, 6165-6168.

48 J. E. Bertie and Z. Lan, J. Phys. Chem. B, 1997, 110, 4111-4119. 49 T. Takamuku, M. Tabata, A. Yamaguchi, J. Nishimoto, M. Kumamoto, H. Wakitaj and T. Yamaguchi, J. Phys. Chem. B, 1998, 102, 8880-8888. 